rats (non pylorus-ligated rats) showed a tendency to prevent gastric damages induced by both i.p. and oral indomethacin but was not however significantly different from control $(\mathrm{P}=0.05)$. The severity of indomethacin-induced gastric lesions in pylorus-ligated rats was slightly reduced as compared to that of intact rats.

From the above results, it is apparent that L-glutamine at rather small doses exerts a strong inhibition on gastric damages induced by indomethacin as well as by aspirin. It appears necessary however that L-glutamine should remain in the stomach for a certain period in order to elicit a significant effect as evidenced by the experiments in pylorusligated and intact rats, although a tendency of inhibition was observed even in cases of i.p. administration of indomethacin in intact rats. L-glutamine given orally to intact rats appears to pass quickly into the duodenum before an adequate effect has been evoked on the gastric mucosi. In the case of aspirin-induced lesions (1), these were evidently aggravated by pylorus ligation in comparison with intact rats, probably as the result of accelerated back diffusion of acid which was obtained from the analysis of gastric contents as suggested in the previous work. Actually, pylorus ligation did not increase the severity of gastric lesions induced by indomethacin but rather reduced the lesions, therefore other mechanisms have to be considered. Recently, Bhargava, Gupta and Tangri (8) reported the involvement of catecholamines released from adrenal medulla in indomethacin-induced gastric lesions in rats. Further study of L-glutamine in relation with such biogenic amines will provide a clue to the etiology of gastric damages caused by indomethacin.

\title{
REFERENCES
}

1) Okabe, S., Takeuchi, K., Nakamura, K, and Takagi, K.: Folia phamacol. japon. 69, 317 (1973) (in Japanese); 2) Rothermich, N.O.: J. Amer. med. Ass. 195, 531 (1966); 3) Menguy, R. and Desbaillets, L.: Am. J. dig. Dis. 12, 862 (1967); 4) Diahanguir1, B.: Scan. J. Gastro. 4, 265 (1969); 5) Lee, Y.H., Mollisox, K.W. And ChfNG, W.D.: Arch. int. Pharmacodym. Ther. 192, $370(1971)$; 6) Shay, H., Komakov, S.A., Flls, S.S., Mlranze, D., Grunstein, M. and Siplet, I1.: Gastroenterology 5, 43 (1945); 7) Brodie, D.A., Tate, L.L. and Hooke, K.F.: Science 170, 183 (1970); 8) Bhargava, K.P., Gupta, M.B. and Tangri, K.K.: Eur. J. Pharmacol. 22, 191 (1973)

\section{DISTRIBUTION OF HISTAMINE IN ADRENAL GLAND}

\author{
Yasuo ENDO and Yasumi OGURA \\ Department of Pharmacology, Schoot of Dentistry. Tohoku University, Sendai, Japan
}

Accepted October 29, 1973

It is known that histamine is widely distributed in many animal tissues, and although the physiological role has been studied, there has been no description of histamine in the Abbreviations: phospho-cellulose (P-cellulose), o-phthalaldehyde (OPT), trihydroxyindole reaction (THI-reaction), 2, 4, 6-trinitrobenzene sulphonate (TNBS), adrenaline (A), noradrenaline (NA), serotonin (5HT), spermidine (Spd), spermine (Spm) 
adrenals. The present study shows the distribution of histamine in the adrenals of guineapig and rat, especially in the cortex region.

Adrenal extract was subjected to P-cellulose column chromatography that permits the separation of some biogenic amines by stcpwise elution with both $\mathrm{pH}$ and ionic strength gradient $(1,2)$. The methods determining amines are as follows: $A$ and NA) measurement of native fluorescence at $285 / 315 \mathrm{~m} / t, \mathrm{H}$ ) OPT-reaction by Shore ct al. (3) with slight modifications (1), Spd and Spm) TNBS-rcaction (1).

Fig. 1-a shows the chromatographic pation of whole adrenal gland of guinea-pig. The position of peak marked with $\mathrm{H}$ corresponds to that of histamine. The substance
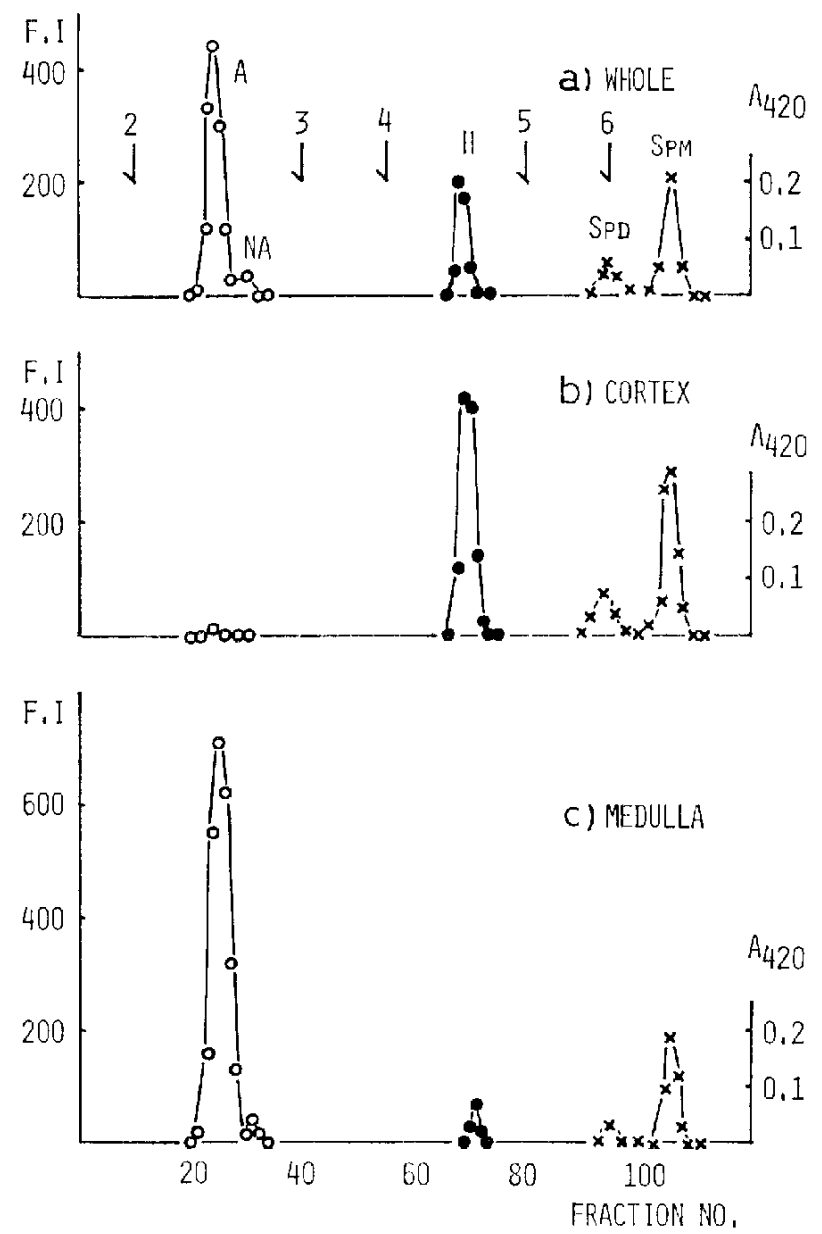

FIG. 1. Chromatographic patterns of adrenal extract of guinea pig.

Adrenals (each $0.35 \mathrm{~g}$ and $0.45 \mathrm{~g}$ ) of a guinea pig (female, $880 \mathrm{~g}$ ) was used. One adrenal gland was divided into cortex $(0.25 \mathrm{~g})$ and medulla $(0.20 \mathrm{~g})$. The experimental procedures were the same as described previously.

F.I. : Fluorescence intensity in both fluorometric assays of catecholamines and histamine.

$\mathrm{A}_{420}$ : Absorbance at $420 \mathrm{~m} \mu$ in TNBS-method.

$\downarrow:$ Buffer change positions. 
in the peak fraction showed the same fluorescence spectrum as histamine and contructive action to the isolated ileum of guinea-pig that was blocked by antihistamine, diphenhydramine. From these results it was concluded that lie substance is histamine.

In comparing both chromatographic patterns of adrenal cortex and medulla (Fig. 1-b and c), most of adrenat histamine was found in the cortex region. This situation is different from that of catecholamine distributed in the medulla region. The amount of hislamine in the cortex region was $30-60 \mathrm{nmoles} / \mathrm{g}$ and that in medulla region was about 2 nmoles/g. With respect

to other biogenic amines also separable in column chromatography, 5HT was hardly detectable and the levels of Spd and Spm in the cortex region were slightly higher (2-3 times) than those in medulla region.

In the rat, also, most of adrenal histamine was found in the cortex region. The contents of histamine in various tissues in at are shown in Table 1. The content of adrenal histamine is higher than that of liver, kidneys, testes and brain and of the similar order as Iungs, spleen and heart.

With respect to endocrine tissues, although very high values of histamine have been reported, 100 mmoles/g in rat thymus (4), more than 500 nmoles/g in rat thyroid gland (5). physiological roles for histamine in these glands have never been established (5). Szego has postulated a mediator role for histamine in the actions of estrogens on the uterus (6). It would be of interest to study the role of adrenal histamine in relation to the actions of the adrenal gland.

\section{REFERI:NCES}

1) Endo, Y. and Ogura, Y.: Liw. J. Halmalol. 21, 293 (1973); 2) ENdo, Y, ANd Oglra, Y.: Japan. J. Pharmacol. 23, 491 (1973); 3) Sirore, P.A., Blikhaltle, A. ANd Cohn, Y.H.JR.: J. Pharmacol. exp. Thet 127, 182 (1959); 4) BlAvin, M.A., Jacobsex, S. AND HorÁkovi, Z.: Chin Chim. Acta 37, 91 (1972); 5) HARviY, S.C.. Arch. int. Phamorodyn. Ther 197, 189 (1972); 6) Szego, C.M.: Fodm. Proc. 24. 1343 (1965) 